\title{
Fouling of polymer and organic-inorganic membranes during filtration of corn distillery
}

\author{
Yurii Zmievskii ${ }^{1}$, Yuliia Dziazko ${ }^{2}$, Valerii Myronchuk ${ }^{1}$, \\ Ludmyla Rozhdestvenska ${ }^{2}$, Alexander Vilenskii ${ }^{3}$, Ludmyla Kornienko'
}

1 - National University of Food Technologies, Kyiv, Ukraine

2 - V.I. Vernadsky Institute of General and Inorganic Chemistry of the National

Academy of Science, Kyiv, Ukraine

3 - A.V. Shubnikov Institute of Crystallography of the RAS, Moscow, RF

Keywords:

Distillery

Membrane

Nanoparticle

Separation

Modification

\section{Article history:}

Received 10.11.2016

Received in revised

form 18.12.2016

Accepted 27.12.2016

\section{Corresponding \\ author:}

Yurii Zmievskii

E-mail:

yrazm@meta.ua

DOI: $10.24263 / 2304-$

974X-2016-5-4-13

\section{Abstract}

Introduction. Baromembrane separation is the most commonly used method for processing of corn distillery. In order to prevent fouling, polymer membranes are hydrophilized modified with particles of inorganic ion-exchangers. The aim of the investigation was to establish and compare the mechanism of fouling for polymer and composite membranes.

Materials and methods. Polyethyleneterephthalate track microfiltration membrane was modified with aggregates of nanoparticles of zirconium hydrophosphate, the materials were examined with a method of scanning electron microscopy. The pressure test was performed using deionized water as a working liquid. Corn distillery was filtered at $1-4$ bar and $60^{\circ} \mathrm{C}$.

Results and discussion. The models of pore blockage, pore constriction and cake formation were applied, particularly to water filtration through the composite membrane. Pore blockage and pore constriction were shown to be possible during pressure test at $60^{\circ} \mathrm{C}$, this can be caused by transformation of porous structure of the polymer and fragmentation of the modifier. Regarding corn distillery, the composite membrane demonstrates higher stability against fouling than the pristine separator. Depending on time of filtration, the composite material obeys Darcy's law or shows the maximal flux at 3 bar. The flux of permeate through the pristine membrane decreases with pressure growth due to accumulation of organics. A linear increasing of productivity under similar conditions is characterized for modified membranes. It means that substances, which polluted the membranes, have a smaller hydrodynamic resistance. The mechanism of pore blockage is valid both for the pristine and composite membranes. Increasing in pressure enhances pore constriction (pristine membrane) and cake formation (all separators). Composite membranes have higher resistance to fouling that allows to use smaller amount of chemicals for regeneration, reduce time of regeneration and volume of wastewater.

Conclusions. The inorganic ion-exchanger allows us to improve stability against fouling with components of corn distillery: no fouling has been found at 1 bar. In order to prevent blockage under higher pressure and facilitate the membrane cleaning, location of ZHP particles just near the outer surface is necessary. Organic-inorganic membranes can be applied to other objects of food industry, especially under room and lower temperatures. 


\section{Introduction}

More than 80 licensed plants of alcohol industry operates in Ukraine at present time, [1]. They are able to process 900000 tons of grain per year and obtain 32 millions decalitres of alcohol. Their annual demand of beet molasses is 1.1 million tons, 30 millions decalitres of alcohol are produced from this feedstock. During the alcohol manufacture, a large amount of liquid wastes, such as grain distillery, is produced. These wastes are characterized by high chemical oxygen demand (COD), biological oxygen demand (BOD) and dark brown color [2]. In order to reduce ecological risks, processing of grain distillery is necessary. Baromembrane separation is the most commonly used technique for this purpose [3-7]. Permeate is returned to the fermentation process increasing ethanol yield [8]. This product could be also applied to extraction of proteins [9]. Concentrate is dried and used further as supplements to food for domestic animals [10] and even for production of bread and cookies [11].

Very important problem of baromembrane separation is fouling of polymer membranes with organic species [12]. Modification of the membrane with inorganic constituent allows us to overcome this difficulty $[13,14]$. Hydrophilic inorganic particles inside pores of the membrane are a barrier against fouling with organics [14]. Moreover, in the case of synthetic ion exchangers [15-17], ion exchange membranes [18] or fibrous biomaterials [19], this approach allows us not only to protect them from organic species, but also to improve functional properties [15-19].

The method of polymer modification with hydrated zirconium phosphate (ZHP), functional properties of the membrane and its testing for practical application were considered earlier [14]. Regarding the application to baromembrane processing of grain distillery, further enhancement of the membrane is impossible without knowledge of fouling mechanism. Establishment of this mechanism is a purpose of the investigation.

\section{Materials and methods}

Polyethyleneterephthalate track membrane produced by A.V. Shubnikov Institute of Crystallography of the RAS (RF) was used for the investigations. Through pores of this porous polymer are regular and rather straight [14]. The membrane was modified with ZHP (4.7 mass \%) as described in [14].

Both the pristine (further PM) and composite (CM) membranes were tested. A divided cell was used for baromembrane separation (effective area of the membrane was $2.1 \cdot 10^{-3}$ $\mathrm{m}^{2}$ ), the stack elements are listed in [14]. Deionized water and corn distillery ( $\mathrm{pH} 4.1$, total solids $-73 \mathrm{~g} \mathrm{dm}^{-3}$, COD - 64) was used for investigations. The biological liquid was centrifuged and filtered through the paper filter.

Preliminarily the membranes were pressed (at 1 bar and further at 3 bar) in deionized water at $25^{\circ} \mathrm{C}$, then the same procedure was performed at $60{ }^{\circ} \mathrm{C}$. After the pressure test, water was filtered through the membranes again at $1 \mathrm{bar}$ and $60^{\circ} \mathrm{C}$. Then the cell was filled with corn distillery, which circulated through the concentration compartment without filtration for $1 \mathrm{~h}$ at $60^{\circ} \mathrm{C}$. Further deionized water was filtered at 1 bar and $60{ }^{\circ} \mathrm{C}$. After this, corn distillery was filtered at 1 bar and $60{ }^{\circ} \mathrm{C}$, than water was filtered again. The next procedure was filtration of corn distillery at 3 bar and $60^{\circ} \mathrm{C}$ followed by water filtration at at $1 \mathrm{bar}$ and $60^{\circ} \mathrm{C}$. At last, corn distillery was filtered at 4 bar and $60^{\circ} \mathrm{C}$. 


\section{Results and discussion}

\section{Pressure test}

For example, Figure 1 shows cumulative volume $(V)$ of permeate (deionized water) through the PM and $\mathrm{CM}$ as a function of time $(\tau)$. As seen, increasing in pressure drop $(\Delta P)$ causes intensification of water transport in accordance to Darcy equation [20]:

$$
J=\frac{\Delta P}{\eta R_{m}}
$$

Here $J$ is the flux ( $J=\frac{d V}{d \tau} \frac{1}{A}$, where $A$ is the membrane area), $\eta$ is the dynamic viscosity of a liquid, $R_{m}$ is the hydrodynamic resistance of a membrane. The modified membrane is less sensitive to pressure than the pristine separator. As shown in [14], aggregates of ZHP particles block macropores (about $300 \mathrm{~nm}$ ) of the polymer increasing hydrodynamic resistance. Similar phenomenon has been found for ceramic membrane containing incorporated particles of inorganic ion-exchangers [21, 22].

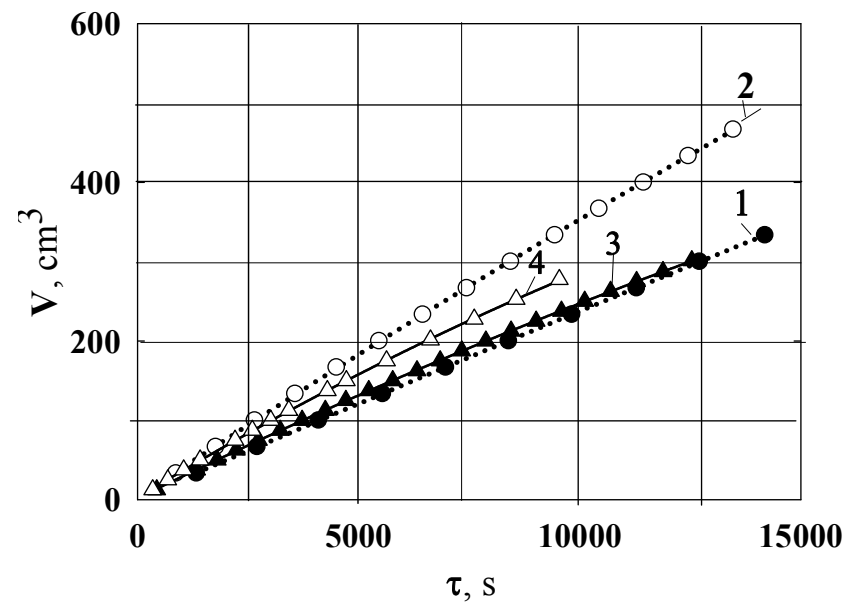

Figure 1. Filtration of deionized water at $60^{\circ} \mathrm{C}$ :

cumulative volume of permeate through $P M(1,2)$ and $C M(3,4)$ as a function of time. Pressure drop: $1(1,3)$ and 3 bar $(2,4)$.

In the case of modified membranes, the inorganic particles can be considered as contaminants. According to known theory of fouling, the fouling mechanism is pore blockage (primary particles or their aggregates are comparable with pores of polymer), if the $J-V$ curve is linear [21]. Pore constriction (deposition of particles on pore walls) is realized, when the $\frac{\tau}{V}-\tau$ curve is approximated by linear polynomial. At last, linearity of the $\frac{\tau}{V}-V$ curve indicates the cake model (precipitation on the outer surface of the membranes). 
Regarding water filtration through $\mathrm{CM}$, only pore constriction and pore blockage models can be applied. No fouling model is suitable for the process at $25^{\circ} \mathrm{C}$ (practically no Change of flux at 1 bar and no linearity of the $\frac{\tau}{V}-\tau$ curve). At the same time, pore blockage and pore constriction models are applicable at $60{ }^{\circ} \mathrm{C}$ (Figure 2). It could be explained by polymer squeezing and pore deformation (formation of their narrowingswidenings). This leads to an increase of hydrodynamic resistance On the other hand, partial fragmentation of ZHP aggregates is possible. The primary particles, which leave the aggregates, can block voids between the next aggregate. On the other hand, the particles are deposited on walls of pores due to turbulence of water flow inside pores (centrifugal force appears as a result of vortex).
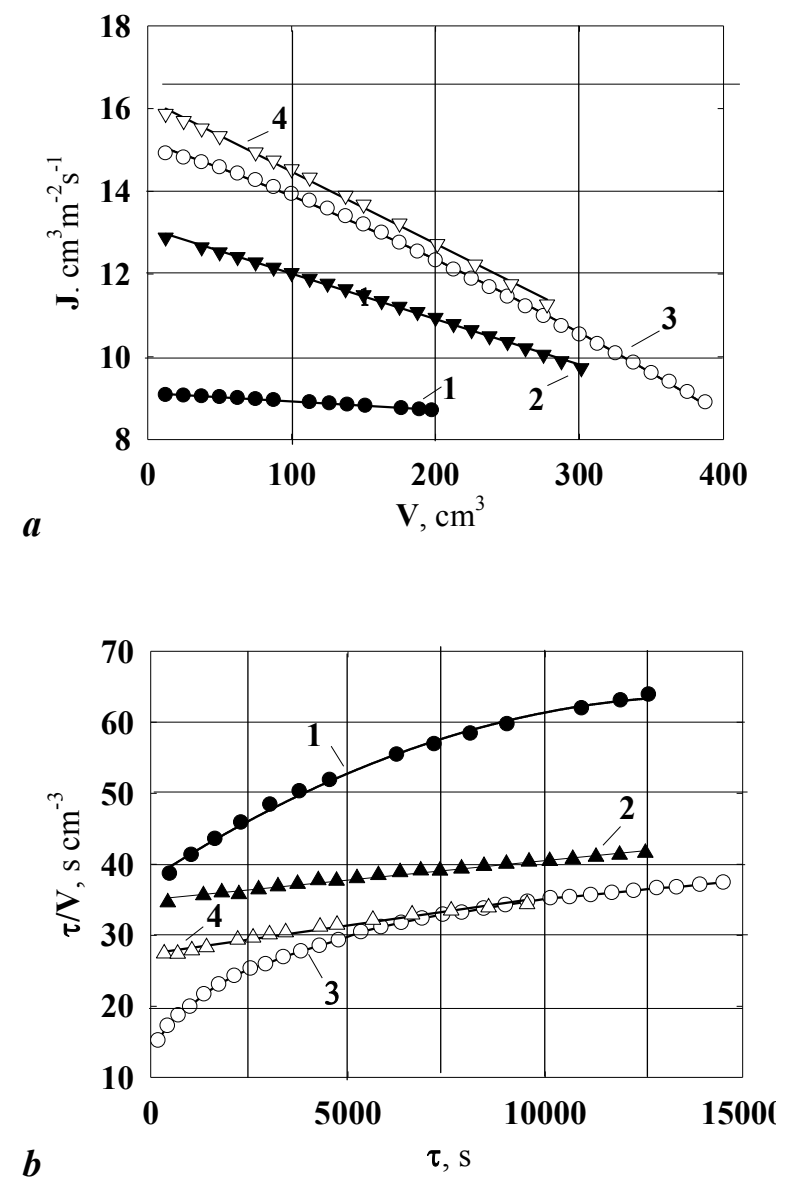

Figure 2. Application of pore blockage (a) and pore constriction (b) models to water filtration through CM.

Filtration was carried out at $1(1,2)$ and $3(3,4)$ bar, at $25(1,3)$ and $60{ }^{\circ} \mathrm{C}(2,4)$. 


\section{- Processes and Equipment of Food Productions -}

The last assumption is confirmed by Figure 3, which illustrates water flux for different stages of water filtration. CM shows more rapid decrease of water flux than PM during water filtration at 1 and 3 bar $\left(60^{\circ} \mathrm{C}\right)$, though the inorganic particles should prevent deformation of the polymer. In the case of PM, decrease of the $J$ value is due to polymer deformation. After the pressure test, both the pristine and composite membranes show lower flux of water due to transformation of porous structure on the one hand and lower temperature on the other hand. No sufficient change of the flux has been found after adsorption of corn distillery.

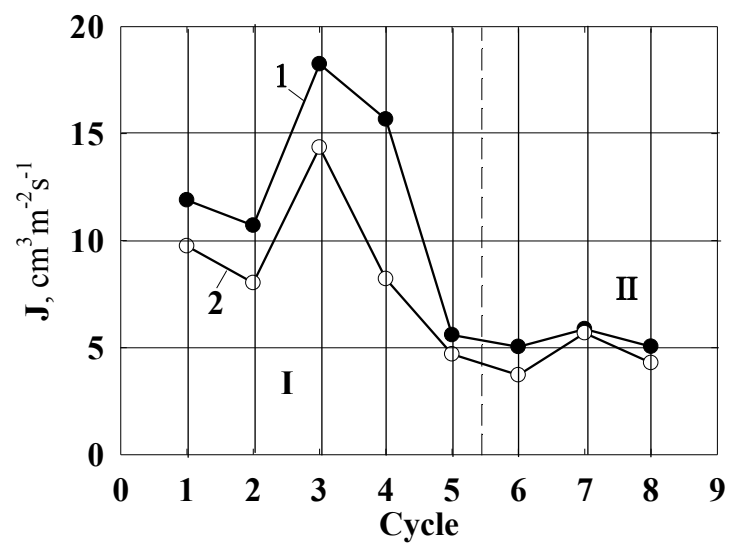

Figure 3. Water flux for different cycles of water filtration (numbers of abscissa axis): beginning (1) and end (2) of the process at $60^{\circ} \mathrm{C}$ and 1 bar, beginning (3) and end (4) of the process at $60^{\circ} \mathrm{C}$ and $3 \mathrm{bar}$, further filtration at $25^{\circ} \mathrm{C}$ and 1 bar (5), after distillery adsorption without filtration (6), after distillery filtration at $60^{\circ} \mathrm{C}$ and 1 bar (7) or 3 bar (8). The region I corresponds contact of membranes with distillery, the region II is related to water filtration after the processes that involve distillery. Curve 1 is related to $P M$, curve $\mathbf{2}$ is for $\mathrm{CM}$

\section{Filtration of corn distillery}

In opposite to PM, the flux of permeate through $\mathrm{CM}$ remains without changes $(\mathrm{CM}, 1$ bar) indicating stability of the composite membrane against fouling. In the other cases, the flux decreases over time. This values reduces slower for $\mathrm{CM}$ than for PM at 3 bar. Alternatively $\mathrm{CM}$ shows faster decrease of the flux at 4 bar probably due to stronger pressing of the, which occurs simultaneously with filtration. On the other hand, fragmentation of ZHP aggregates can be reinforced under these conditions. Regarding CM, the initial flux obeys Darcy law (Figure 5). However, the final one demonstrates a maximum at 3 bar. Both the initial and final flux fall with pressure in the case of PM evidently due to fouling. No sufficient change of water flux has been found after filtration of corn distillery (see Figure 3).

The model of pore blockage can be applied to all membranes, since approximation of the curves with linear polynomial gives the same correlation coefficient as for quadratic polynomial (Table 1, see also Figure 4). In the case of pristine membrane, increasing in pressure drop enchances the tendency to pore constriction and cake formation. Three these mechanisms are valid simultaneously at 4 bar. Regarding CM, only pore blockage and cake formation are realized under these conditions. 

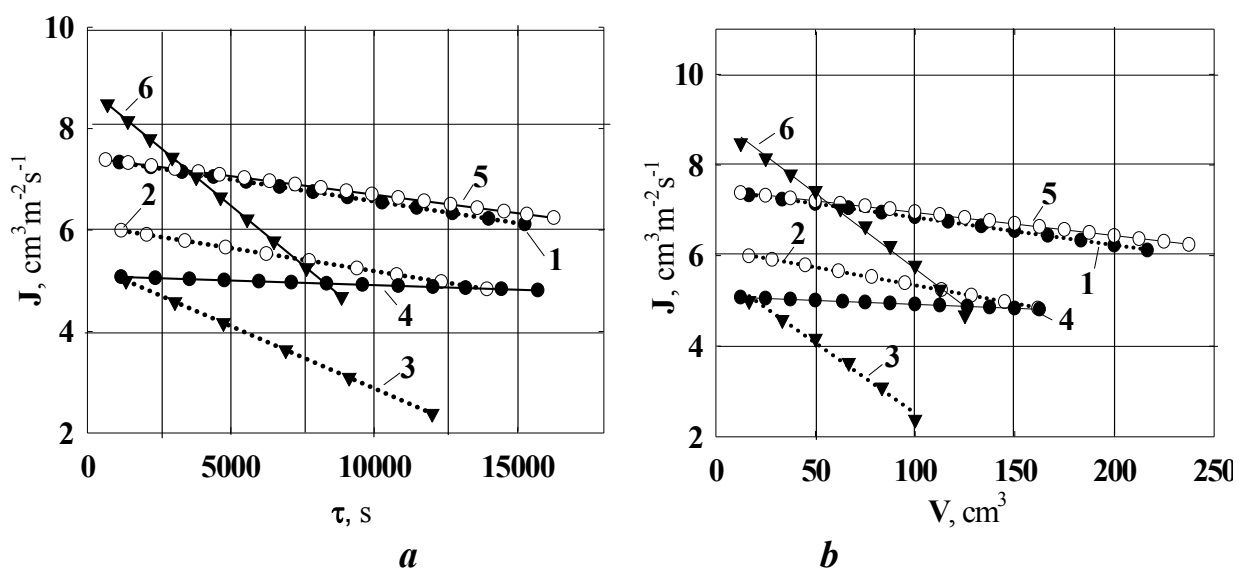

b
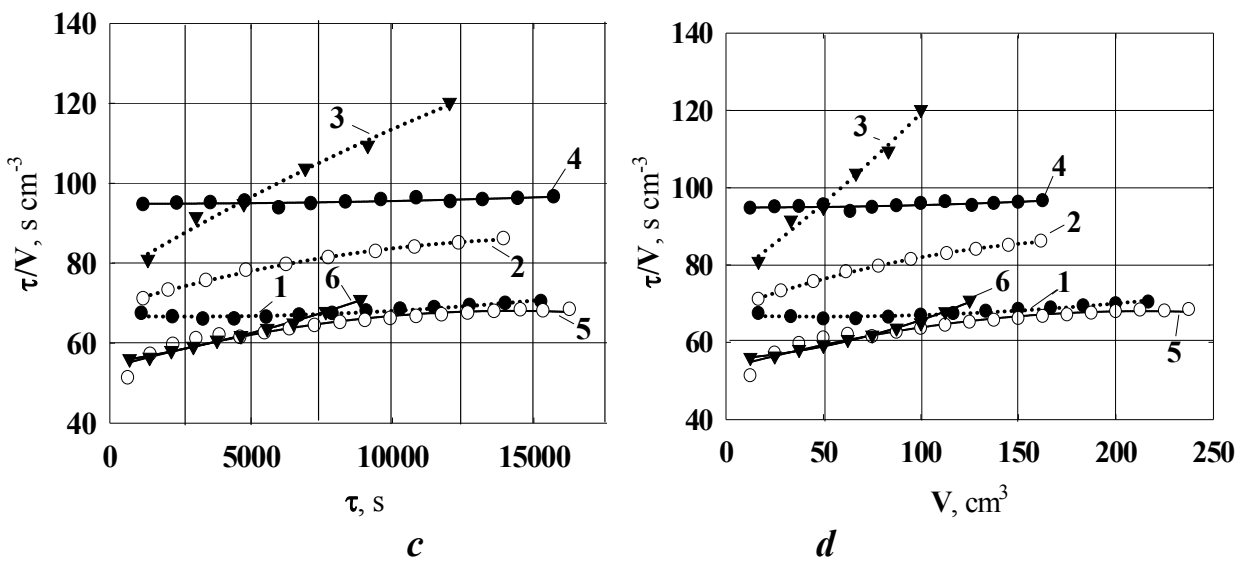

Figure 4. Filtration of corn distillery at $60^{\circ} \mathrm{C}$ :

permeate flux as a function of time (a), models of pore blockage (b), pore constriction (c) and cake formation (d);

Membranes: PM (1-3), CM (4-6); Pressure: 1 (1, 4), 3 (2, 5), 4 (3, 6) bar.

Table 1

Application of different models to filtration of corn distillery at $60^{\circ} \mathrm{C}$

\begin{tabular}{|l|c|c|c|c|c|c|c|}
\hline Membrane & Pressure, & \multicolumn{2}{|c|}{ Pore blockage, $\boldsymbol{R}^{2}$} & \multicolumn{2}{c|}{ Pore constriction, $\boldsymbol{R}^{2}$} & \multicolumn{2}{c|}{ Cake formation, $\boldsymbol{R}^{2}$} \\
\cline { 3 - 8 } & & $\begin{array}{c}\text { Linear } \\
\text { polynomial }\end{array}$ & $\begin{array}{c}\text { Quadratic } \\
\text { polynomial }\end{array}$ & $\begin{array}{c}\text { Linear } \\
\text { polynomial }\end{array}$ & $\begin{array}{c}\text { Quadratic } \\
\text { polynomial }\end{array}$ & $\begin{array}{c}\text { Linear } \\
\text { polynomial }\end{array}$ & $\begin{array}{c}\text { Quadratic } \\
\text { polynomial }\end{array}$ \\
\hline \multirow{3}{*}{ PM } & 1 & 0.99 & 0.99 & 0,81 & 0,92 & 0,80 & 0.93 \\
\cline { 2 - 8 } & 3 & 0.99 & 0.99 & 0,95 & 0.99 & 0.97 & 0.99 \\
\cline { 2 - 8 } & 4 & 0.98 & 0.99 & 0.98 & 0.99 & 0.98 & 0.98 \\
\hline \multirow{3}{*}{ CM } & 1 & - & - & - & - & - & - \\
\cline { 2 - 8 } & 3 & 0.99 & 0.99 & 0.53 & 0,57 & 0.83 & 0.93 \\
\cline { 2 - 8 } & 4 & 0.98 & 0.99 & 0,82 & 0.92 & 0.99 & 0.99 \\
\hline
\end{tabular}




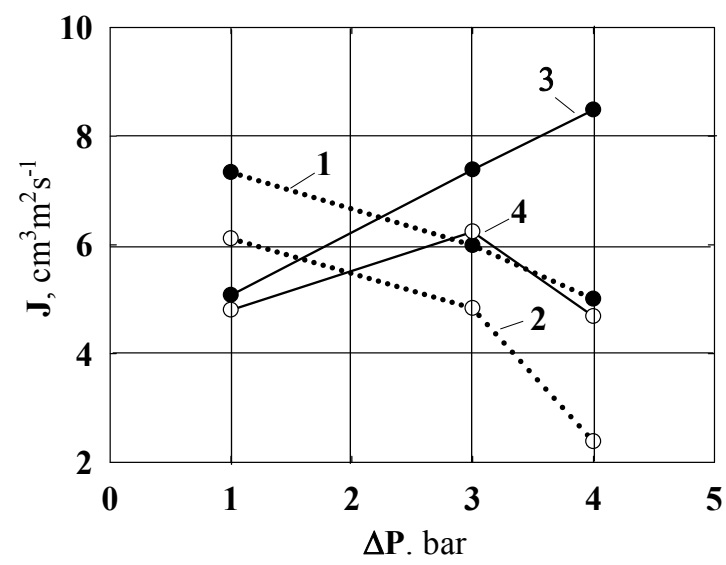

Figure 5. Filtration of corn distillery at $60^{\circ} \mathrm{C}$ trough PM $(1,2)$ and $\mathrm{CM}(3,4)$ : initial $(1,3)$ and final $(2,4)$ permeate flux as a function of pressure drop

Since no sufficient change of water flux after filtration, the "corks" of organics occupy insignificant volume of pores of the polymer. Regarding CM, organics can block pores between ZHP nanoparticles of the aggregates.

\section{Conclusions}

ZHP affects permeability of the track membrane. During pressure test under elevated temperature, the flux of deionized water can be caused by not only transformation of porous structure of the polymer, but also by fragmentation of the modifier aggregates. This phenomenon is not observed under room temperature. The inorganic ion-exchanger allows us to improve stability against fouling with components of corn distillery: pore constriction is not realized for $\mathrm{CM}$ in opposite to PM. Moreover, no fouling has been found at $60^{\circ} \mathrm{C}$ and 1 bar. In order to prevent blockage under higher pressure and facilitate the membrane cleaning, location of ZHP particles just near the outer surface is necessary. The improvement of the modification technique is a subject of further investigations.

Increasing in pressure leads to intensification of cake formation. However, the precipitate can be easy removed from the outer surface of the membrane by means of hydrodynamic pulsations.

Due to stability against fouling, organic-inorganic membranes can be applied to other objects of food industry, especially under room and lower temperatures.

\section{References}

1. Shamanska O. I., Palamarenko Y. V (2014), Modern trends in the alcohol industry of Ukraine, Efectyvna economica, 4, available at:

http://www.economy.nayka.com.ua/?op=1\&z=2903 


\section{- Processes and Equipment of Food Productions-}

2. Bustamante M.A., Paredes C., Moral R., Moreno-Caselles J., Perez-Espinosa A., Perez-Murcia M.D. (2005), Uses of winery and distillery effluents in agriculture: characterization of nutrient and hazardous components, Water Science and Technologies, 51(1), pp. 145-151.

3. Vasic V. M., Sciban M. B., Prodanovic J. M., Kukic D. V. (2013), Characterization and utilization of the permeate and retentate obtained after "dead-end" ultrafiltration, Acta Periodica Technologia, 44, pp. 163-170.

4. Wu Y. V. (1988), Recovery of stillage soluble solids from corn and dry-milled corn fractions by high-pressure reverse osmosis and ultrafiltration, Cereal Chemistry, 65(4), pp. 345-348.

5. Lapisova K., Vlcek R., Klozova J., Rychtera M., Melzoch K. (2006), Separation techniques for distillery stillage treatment, Czech Journal of Food Science, 24(6), pp. 261-267.

6. Kornienko L., Zmievskii Yu., Myronchuk V. (2015) Investigation of ultrafiltration of grain stillage, Ukrainian Food Journal, 4(1), pp. 131-138.

7. Prodanovic J.M., Vasic V.M. (2013), Application of membrane processes for distillery wastewater purification - a review, Desalination and Water Treatment, 51(16-18), pp. 3325-3334.

8. Kim J.-S., Kim B.-G., Lee Ch.-H., Kim S.-W., Jee H.S., Koh J.-H., Fane A.G. (1997), Development of clean technology an alcohol fermentation industry, Journal of Cleaner Production, 5(4), pp. 263-267.

9. Mojovic L., Pejin D., Rakin M., Pejin J., Nikolic S., Djukic-Vukovic A. (2012), How to improve the economy of bioethanol production in Serbia, Renewable and Sustainable Energy Reviews, 16, pp. 6040-6047.

10. Ratanapariyanuch K., Tyler R.T., Shim Y.Y., Reaney M.J.T. (2012) Biorefinery process for protein extraction from oriental mustard (Brassica juncea (L.) Czern.) using ethanol stillage, $A M B$ Express, 2, pp. 5.

11. Tsen C.C., Eyestone W., Weber J. L. (1983), Evaluation of the qualities of cookies supplemented with the distillers' dried grain flours, Journal of Food Science, 47, pp. 484.

12. Lee S.J., Kim J.H. (2014), Differential natural organic matter fouling of ceramic versus polymeric ultrafiltration membranes, Water Research, 48(1),pp. 43-51.

13. Safarpour M., Khataee A., Vatanpou V. (2015), Effect of reduced graphene oxide/TiO2 nanocomposite with different molar ratios on the performance of PVDF ultrafiltration membranes, Separation and Purification Technology, 140, pp. 32-42.

14. Dzyazko Yu. S., Rozhdestvenskaya L.M., Zmievskii Yu. G., Vilenskii A.I., Myronchuk V.G., Kornienko L.V., Vasilyuk S.L., Tsyba N.N. (2015), Organicinorganic materials containing nanoparticles of zirconium hydrophosphate for baromembrane separation, Nanoscale Research Letters,. 10, pp. 64-75.

15. Dzyazko Yu.S., Ponomaryova L.N., Volfkovich Yu.M., Sosenkin V.E., Belyakov V.N. (2013) Polymer Ion-Exchangers Modified with Zirconium Hydrophosphate for Removal of $\mathrm{Cd}^{2+}$ Ions from Diluted Solutions, Separation Science and Technology, 48(14), pp. 2140-2149.

16. Dzyazko Y.S., Ponomaryova L.N., Rozhdestvenskaya L.M., Vasilyuk S.L., Belyakov V.N. (2014), Electrodeionization of low-concentrated multicomponent $\mathrm{Ni}^{2+}$ containing solutions using organic-inorganic ion-exchangers, Desalination, 342, pp. 52-60.

17. Dzyazko Yu. S., Ponomaryova L. N., Volfkovich Yu. M., Trachevskii V.V., Palchik A.V. (2015) Ion-exchange resin modified with aggregated nanoparticles of zirconium 
hydrophosphate. Morphology and functional properties, Microporous and Mesoporous Materials, 198, pp. 55-62.

18. Dzyazko Yu., Rozhdestveskaya L., Zmievskii Yu., Volfkovich Yu., Sosenkin V., Nikolskaya N., Vasilyuk S., Myronchuk V., Belyakov V. (2015) Heterogeneous Membranes Modified with Nanoparticles of Inorganic Ion-Exchangers for Whey Demineralization, Materials Today: Proceedings, 2(6), pp. 3864-3873.

19. Mokrousova E.R., Dzyazko Yu.S., Volfkovich Yu.M., Nikolskaya N.F, Hierarchical Structure of the Derma Affected by Chemical Treatment and Filling with Bentonite: Diagnostics with a Method of Standard Contact Porosimetr. In Nanophysics, Nanophotonics, Surface Studies, and Applications (O. Fesenko, L. Yathenko, eds.): Springer Proceedings Phys., Switzerland, 2016, V. 183. - p. 277-290.

20. Mulder M. (2000) Basic principles of membrane technology, Kluwer, Dordrecht.

21. Dzyazko Yu.S., Rudenko A.S., Yukhin Yu.M., Palchik A.V., Belyakov V.N. (2014), Modification of ceramic membranes with inorganic sorbents. Application to electrodialytic recovery of $\mathrm{Cr}(\mathrm{VI})$ anions from multicomponent solution, Desalination, 342, pp. 43-51.

22. Dzyazko Yu.S., Volfkovich Yu.M., Sosenkin V. E., Nikolskaya N.F., Gomza Yu.P. (2014), Composite inorganic membranes containing nanoparticles of hydrated zirconium dioxide for electrodialytic separation, Nanoscale Research Letters, 9(1), pp. $271-282$.

23. Ho C.C., Zydney A.L. (2000), A Combined Pore Blockage and Cake Filtration Model for Protein Fouling during Microfiltration, Journal of Colloid and Interface Science, 232, pp. 389-399. 